\title{
Alterações nos atributos químicos de solo arenoso pela calagem superficial no sistema plantio direto consolidado ${ }^{1}$
}

\author{
Changes in properties of a sandy soil under no tillage by surface liming
}

\author{
Luciano Colpo Gatiboni ${ }^{2}$ Adair Saggin ${ }^{3}$ Gustavo Brunetto ${ }^{3}$ Delson Horn ${ }^{3}$ \\ João Paulo Cassol Flores ${ }^{3}$ Danilo dos Santos Rheinheimer ${ }^{4}$ João Kaminski ${ }^{5}$
}

\section{RESUMO}

A forma aplicação de calcário no sistema plantio direto (SPD) cria no solo um gradiente de concentração dos produtos de sua reação. O objetivo do presente trabalho foi avaliar os atributos químicos relacionados à acidez de solo após sete anos da aplicação de calcário superficialmente no solo sob SPD. O experimento foi realizado no Departamento de Solos da Universidade Federal de Santa Maria, num Argissolo Vermelho distrófico arênico. O experimento foi instalado em outubro de 1994 em solo conduzido sob SPD desde 1988. Os tratamentos consistiram numa testemunha sem calcário e na reaplicação superficial de calcário para elevar o pH a 6,0, adicionando a dose recomendada, totalmente no início do experimento; metade da dose no início e a outra metade no terceiro ano; e um terço da dose a cada ano, nos três primeiros anos. $O$ delineamento experimental utilizado foi de blocos ao acaso, com quatro repetições. Em outubro de 2001, 84 meses após, foram abertas três trincheiras por parcela e coletadas amostras de solo em camadas de $1 \mathrm{~cm}$ até os 10 $\mathrm{cm}$ de profundidade, de $2,5 \mathrm{~cm}$ até os $25 \mathrm{~cm}$, de $5 \mathrm{~cm}$ até os 50 $\mathrm{cm}$ e da camada de $50-60 \mathrm{~cm}$. A aplicação superficial de calcário proporcionou uma frente alcalinizante no perfil do solo e migração de Ca e $\mathrm{Mg}$ em todo horizonte A.

Palavras-chave: calcário, acidez do solo, saturação com alumínio,movimento de cátions, bioporos.

\section{ABSTRACT}

Surface liming of soil under no-tillage forms a concentration gradient of lime or its reaction products in the soil profile. The objective of this study was to evaluate the effects of surface liming on chemical attributes related to soil acidity. The experiment was carried out at the Federal University of Santa Maria, Southern Brazil, on a Typic Hapludult. The experiment was installed in October 1994 on a soil under no tillage since 1988. The treatments were: without lime; superficial reapplication of lime to elevate the $\mathrm{pH}$ to 6.0, totally added in the beginning of the experiment; half of the lime requirement in the beginning and the other half at the third year and a third of lime requirement, each year, during the first three years. The experimental design was completely randomized blocks with four replications. In October 2001, 84 months after liming, three trenches per plot were open and the soil sampled in layers of $1 \mathrm{~cm}$ to $10 \mathrm{~cm}$ of depth, of $2,5 \mathrm{~cm}$ to $25 \mathrm{~cm}$, of $5 \mathrm{~cm}$ to $50 \mathrm{~cm}$ and the layer of 50 $60 \mathrm{~cm}$. Surface applied lime was effective in neutralizing soil acidity in the soil profile and caused migration of calcium and magnesium in all the $A$ horizon.

Key words: lime, soil acidity, alluminum saturation, movement of cations, biopores.

\section{INTRODUÇÃo}

A acidificação do solo é um processo natural e sua intensidade depende de fatores intrínsecos do solo e das perturbações a que o sistema é submetido (KAMINSKI \& RHEINHEIMER, 2000). A magnitude e a velocidade dos processos de reacidificação do solo no sistema plantio direto (SPD) são diferentes daquelas apresentadas pelo sistema de cultivo convencional (SCC) (PAIVA et al., 1996). Atualmente, a utilização do

${ }_{1}$ Trabalho financiado pelo CNPq/PRONEX.

2 Engenheiro Agrônomo, Mestre em Agronomia, Doutorando no Programa de Pós-Graduação, Universidade Federal de Santa Maria (UFSM), 97105-900, Santa Maria-RS.

${ }^{3}$ Acadêmico do Curso de Agronomia da UFSM.

${ }^{4}$ Engenheiro Agrônomo, Doutor em Ciência do Solo, Professor Adjunto, Departamento de Solos, UFSM, Campus Universitário, 97105-900, Santa Maria-RS. E-mail: danilo@ccr.ufsm.br. Autor para correspondência.

${ }_{5}^{5}$ Engenheiro Agrônomo, Doutor em Ciência do Solo, Professor colaborador, Departamento de Solos, UFSM e Professor da Universidade Franciscana. 
SPD atinge mais de $60 \%$ da área cultivada com culturas anuais no Rio Grande do Sul (FERREIRA et al., 1999). Embora já se tenha recomendação para a aplicação superficial de calcário (CFS-RS/SC, 1994), há dúvidas quanto aos critérios referentes às doses e freqüência de reaplicação.

A correção da acidez do solo no SCC pressupõe a incorporação do calcário através de arações e gradagens, práticas características desse sistema. Porém, esse manejo provoca alterações das características físicas do solo, como a desestabilização dos agregados e a diminuição da porosidade, aumentando o escoamento superficial, potencializando o processo de erosão do solo e perdas de nutrientes. Assim, a camada de solo corrigida pode ser facilmente erodida e a necessidade de reaplicação do calcário torna-se mais freqüente.

Já no SPD, o corretivo da acidez do solo é aplicado superficialmente, podendo as partículas finas deslocar-se para camadas mais profundas, pois há boas características físicas. Assim, ocorre aumento do $\mathrm{pHe}$ neutralização do Al monomérico na subsuperfície (AMARAL et al., 2001). Os bioporos, também, podem se tornar caminhos preferenciais na movimentação descendente da solução do solo e partículas finas. A migração dos efeitos da calagem em profundidade está relacionada, principalmente, à dose de corretivo, ao tempo de avaliação, aos atributos do solo, especialmente os teores de colóides, à macroporosidade e ao regime hídrico e, secundariamente, à presença de ânions inorgânicos, como nitratos, sulfatos, cloretos e silicatos e ânions orgânicos (PEARSON et al.,1962, HAYNES \& MOKOLOBATE, 2001). A decomposição dos resíduos vegetais a partir da superfície do solo origina compostos orgânicos hidrossolúveis, os quais têm sido apontados com sendo os responsáveis pela complexação de $\mathrm{Ca}$ nas camadas superficiais, seguido de migração no perfil do solo. Em solução do solo com a presença de Al, há liberação do Ca e complexação do Al, diminuindo sua fitotoxidade e aumentando o teor de Ca no perfil do solo (HAYNES \& MOKOLOBATE, 2001).

No sul do Brasil, há vários trabalhos que relatam os efeitos da aplicação de calcário na superfície do solo no sistema plantio direto (OLIVEIRA \& PAVAN, 1996; CAIRES et al., 1998 e 1999; POTTKER \& BEN, 1998; AMARAL, 1998; POTTKER et al., 1998; NETO et al., 2000; RHEINHEIMER et al., 2000a e b; KAMINSKI et al., 2000). Dentre esses trabalhos, destacam-se aqueles desenvolvidos em solos do Paraná, como os de CAIRES et al. (1998, 1999 e 2000) e NETO et al. (2000), cuja diminuição do Al trocável e aumento nos teores de $\mathrm{Ca}$ e $\mathrm{Mg}$ e no $\mathrm{pH}$ do solo ocorreram até os $10 \mathrm{~cm}$ de profundidade, já aos 3-12 meses após a aplicação e atingindo os $20 \mathrm{~cm}$ aos 40-58 meses após a aplicação, embora tenha neutralizado todo o Al trocável apenas na camada $0-5 \mathrm{~cm}$. Similarmente, esse comportamento ocorreu nos solos do Planalto do Rio Grande do Sul, onde a neutralização total do Al trocável ficou limitada à camada de $0-5 \mathrm{~cm}$, mesmo com doses superiores a $1 \frac{1}{2}$ da recomendação, aos 34 e 42 meses após a aplicação (POTTKER \& BEN, 1998; PETRERE e ANGHINONI, 2001; MOREIRA et al., 2001). Quando as coletas de amostras de solos são feitas em camadas menos espessas, nota-se que a neutralização de todo o Al trocável ocorre em menores profundidades, como observado nos trabalhos de CASSOL (1995); AMARAL (1998), KAMINSKI et al. (2000) e RHEINHEIMER et al. (2000b).

A melhoria nos atributos químicos do solo, em profundidade, decorrentes da calagem superficial, é proporcional a dose do corretivo. Os trabalhos de POTTKER \& BEN (1998), RHEINHEIMER et al. (2000b)e PETRERE \& ANGHINONI (2001) mostraram que, com a aplicação de doses menores do que a metade da recomendada para elevar o $\mathrm{pH}$ do solo a 6,0 , os efeitos ficaram limitados até $5 \mathrm{~cm}$ de profundidade, mais ainda com presença de Al trocável; enquanto em doses superiores, esse efeito se estendeu até aproximadamente $20 \mathrm{~cm}$ de profundidade, com neutralização total do $\mathrm{Al}$ trocável até os $5 \mathrm{~cm}$.

Outro fator importante quanto à acidez do solo e estratégias para a sua correção é o conhecimento da residualidade do corretivo. AZEVEDO et al. (1996) observaram que, mesmo após 23 anos da calagem, o solo ainda mantinha o $\mathrm{pH}$ e os teores de $\mathrm{Ca}$ e $\mathrm{Mg}$ trocável mais elevados e de $\mathrm{Al}$ trocável mais baixo, em relação ao solo natural. Esse comportamento leva ao discernimento de que o solo amortece o impacto do distúrbio provocado pela adição do calcário de tal forma que, dificilmente, a magnitude da acidez retornará aos patamares do solo original. No SCC, há necessidade de reaplicação de calcário a cada 4 a 5 anos, pois o revolvimento do solo acelera os processos de reacidificação e há grandes perdas de corretivo pela erosão, diminuindo o seu efeito residual. Por outro lado, no SPD, devido às melhorias nas características físico-bio-químicas, deve ocorrer um prolongamento da residualidade do calcário.

Este trabalho foi desenvolvido com o objetivo de avaliar os efeitos da aplicação de calcário no solo sob SPD nos atributos químicos relacionados à acidez do solo.

Ciência Rural, v. 33, n. 2, mar-abr, 2003. 


\section{MATERIAL EMÉTODOS}

O experimento foi realizado no Departamento de Solos da Universidade Federal de Santa Maria (RS), em um Argissolo Vermelho distrófico arênico, com 140 $\mathrm{g} \mathrm{kg}^{-1}$ de argila e $11 \mathrm{~g} \mathrm{~kg}^{-1}$ de matéria orgânica. A área foi manejada no SCC até 1988, quando o solo foi lavrado pela última vez e realizada a calagem, estimada para elevar o $\mathrm{pH}$ do solo a 6,0. A partir disso, adotouse o SPD, sendo cultivados milho (Zea mays) e aveia preta (Avena strigosa) + ervilhaca (Vicia sativa) até a safra de 1993/94. Em 1994, coletou-se amostra de solo, cujos resultados químicos foram: $\mathrm{pH}-\mathrm{H}$ O 5,0, índice SMP 5,8, Al trocável 0,40 $\mathrm{cmol} \mathrm{dm}^{-3}, \mathrm{Ca}$ × $\mathrm{Mg}$ trocáveis $3,0 \mathrm{cmol} \mathrm{dm}^{-3}, \mathrm{P}$ disponível $10^{\mathrm{c}} \mathrm{mg} \mathrm{dm}{ }^{-3} \mathrm{e} \mathrm{K}$ trocável 75 $\mathrm{mg} \mathrm{dm}{ }^{-3}$.

Em outubro de 1994, instalou-se o experimento, cujos tratamentos foram baseados na estimativa da correção da acidez para $\mathrm{pH} 6,0$. Os tratamentos consistiram numa testemunha sem calcário e na reaplicação de calcário para elevar o pH a 6,0, adicionando a dose recomendada totalmente no início do experimento, metade da dose no início e a outra metade no terceiro ano e um terço da dose em cada um dos três primeiros anos. O delineamento experimental utilizado foi de blocos ao acaso, com quatro repetições e as parcelas mediram $10 \times 15 \mathrm{~m}$. Cultivou-se milho (safra 94/95), aveia preta (95), soja (Glycine max) (95/96), aveia preta (96), soja (96/97) (RHEINHEIMER et al., 2000a), aveia preta + ervilhaca (97), milho (97/98), aveia preta (98), crotalária (Crotalaria juncea) (98/99) e trigo (Triticum aestivum) safra 99 . No verão de $99 / 00$, cultivou-se milho e, no inverno de 2000, aveia preta. Para as últimas duas culturas, foram determinadas a produção de matéria seca e o rendimento de grãos da cultura comercial. Em cada cultivo comercial, utilizou-se a adubação recomendada pela CFS-RS/SC (1994).

Em outubro de 2001, 84 meses após a aplicação de calcário, foram abertas três trincheiras por parcela e coletadas amostras de solo em camadas de $1 \mathrm{~cm}$ até os $10 \mathrm{~cm}$ de profundidade, de $2,5 \mathrm{~cm}$ até os $25 \mathrm{~cm}$, de $5 \mathrm{~cm}$ até os $50 \mathrm{~cm}$ e da camada de $50-60 \mathrm{~cm}$. As amostras de solo foram secadas em estufa a $55^{\circ} \mathrm{C}$ e passadas em peneira de $2 \mathrm{~mm}$. Foram determinados o $\mathrm{pH}$ $\mathrm{H}_{2} \mathrm{O}$, o índice SMP e os teores de $\mathrm{Ca}, \mathrm{Mg}$ e Al trocáveis (TEDESCO et al., 1995). Com esses resultados, foram calculadas a saturação com $\mathrm{Al}$ e com bases.
Os dados dos atributos químicos do solo foram submetidos à análise de variância e as médias comparadas pelo teste de Tukey $(\mathrm{p}<0,05)$.

\section{RESULTADOS E DISCUSSÃO}

No tratamento testemunha que, em virtude do histórico de ocupação da área, recebera calcário incorporado há treze anos, observou-se um valor de pH 5,2 na camada de $0-1 \mathrm{~cm}$ e valores menores nas camadas inferiores, atingindo $\mathrm{pH} 4,7$ na camada $9-10 \mathrm{~cm}$, pH 4,3 na camada $15-17,5 \mathrm{~cm}$ e pH 4,1 a partir dos $40 \mathrm{~cm}$ (Tabela 1). Mesmo comportamento observou-se para $\mathrm{Ca}$ e $\mathrm{Mg}$ trocáveis, que também diminuíram linearmente em profundidade. Os valores foram de 3,13 e 1,37 $\mathrm{cmol}_{\mathrm{c}}$ $\mathrm{dm}^{-3}$ na camada $0-1 \mathrm{~cm}, 1,61 \mathrm{e} 0,71 \mathrm{cmol}_{\mathrm{c}} \mathrm{dm}^{-3}$ na camada $9-10 \mathrm{~cm}, 1,33$ e $0,35 \mathrm{cmol}_{\mathrm{c}} \mathrm{dm}^{-3}$ na camada $15-17,5 \mathrm{~cm}$ e menor do que $0,81 \mathrm{e} 0,21 \mathrm{cmol}_{\mathrm{c}} \mathrm{dm}^{-3}$ a partir dos $40 \mathrm{~cm}$, respectivamente para $\mathrm{Ca}$ e $\mathrm{Mg}$ (Tabela 2). Já os teores de Al trocável apresentaram valores linearmente crescentes com a profundidade, sendo menor do que $0,71 \mathrm{cmol}_{\mathrm{c}} \mathrm{dm}^{-3}$ até os $10 \mathrm{~cm}$, menores do que $1,50 \mathrm{cmol}_{\mathrm{c}}$ $\mathrm{dm}^{-3}$ até os $20 \mathrm{~cm}$ e superiores a $1,50 \mathrm{cmol}_{\mathrm{c}} \mathrm{dm}^{-3}$ a partir dos $25 \mathrm{~cm}$ de profundidade (Tabela 3 ). Como conseqüência, a saturação com $\mathrm{Al}$ também aumentou linearmente com a profundidade, sendo inferior a $15 \%$ até os $6 \mathrm{~cm}$, inferior a $35 \%$ até os $15 \mathrm{~cm}$, próxima a $45 \%$ até os $25 \mathrm{~cm}$ e maior do que $50 \%$ nas camadas mais profundas (Figura 1). A saturação com bases foi

Tabela 1 - pH- $\mathrm{H}_{2} \mathrm{O}$ em diferentes camadas de solo sob sistema plantio direto após 84 meses da aplicação de doses de calcário

\begin{tabular}{lccccc}
\hline & & \multicolumn{4}{c}{ Doses de calcário media } \\
\cline { 3 - 6 } Profundidade (cm) & Testemunha & $\begin{array}{c}1 / 2 \text { SMP } \\
\text { bienal }\end{array}$ & $\begin{array}{c}1 / 3 \text { SMP } \\
\text { anual }\end{array}$ & 1 SMP & Média \\
\hline $0-1$ & 5,2 & 6,1 & 5,7 & 5,7 & 5,8 \\
$1-2$ & 5,1 & 6,1 & 5,6 & 5,7 & 5,8 \\
$2-3$ & 5,0 & 6,1 & 5,8 & 5,8 & 5,9 \\
$3-4$ & 4,9 & 6,1 & 5,5 & 5,6 & 5,7 \\
$4-5$ & 4,9 & 6,0 & 5,5 & 5,5 & 5,7 \\
$5-6$ & 4,8 & 5,8 & 5,4 & 5,4 & 5,5 \\
$6-7$ & 4,8 & 5,7 & 5,5 & 5,4 & 5,5 \\
$7-8$ & 4,8 & 5,5 & 5,3 & 5,3 & 5,4 \\
$8-9$ & 4,7 & 5,5 & 5,2 & 5,2 & 5,3 \\
$9-10$ & 4,7 & 5,4 & 5,2 & 5,2 & 5,3 \\
$10-12,5$ & 4,4 & 5,1 & 5,1 & 4,8 & 5,0 \\
$12,5-15$ & 4,4 & 4,9 & 5,0 & 4,9 & 4,9 \\
$15-17,5$ & 4,3 & 4,9 & 4,9 & 4,8 & 4,9 \\
$17,5-20$ & 4,3 & 4,9 & 4,8 & 4,9 & 4,9 \\
$20-22,5$ & 4,3 & 5,0 & 4,8 & 5,0 & 4,9 \\
$22,5-25$ & 4,3 & 4,7 & 4,9 & 4,8 & 4,8 \\
$25-30$ & 4,4 & 4,7 & 4,9 & 5,0 & 4,9 \\
$30-35$ & 4,4 & 4,7 & 4,9 & 4,8 & 4,8 \\
$35-40$ & 4,3 & 4,8 & 4,9 & 4,8 & 4,8 \\
$40-45$ & 4,1 & 4,6 & 4,6 & 4,6 & 4,6 \\
$45-50$ & 4,1 & 4,4 & 4,6 & 4,4 & 4,5 \\
$50-60$ & 4,1 & 4,4 & 4,5 & 4,6 & 4,5 \\
$\Delta q$ Tukey $(\mathrm{p}<0,05)$ & & & & & 0,46 \\
\hline
\end{tabular}

Ciência Rural, v. 33, n. 2, mar-abr, 2003. 
Tabela 2 - Cálcio e magnésio trocáveis em diferentes camadas de solo sob sistema plantio direto, após 84 meses da aplicação de doses de calcário

\begin{tabular}{|c|c|c|c|c|c|c|c|c|c|c|}
\hline \multirow{2}{*}{$\begin{array}{l}\text { Prof. } \\
\text { (cm) }\end{array}$} & \multicolumn{5}{|c|}{ Doses de calcário } & \multicolumn{5}{|c|}{ Doses de calcário } \\
\hline & Zero & 1/2 SMPbienal & $1 / 3$ SMP anual & $1 \mathrm{SMP}$ & Média & Zero & 1/2 SMP bienal & 1/3 SMP anual & $1 \mathrm{SMP}$ & Média \\
\hline & \multicolumn{5}{|c|}{ Cálcio $\left(\mathrm{cmol}_{\mathrm{c}} \mathrm{dm}^{3}\right)$} & \multicolumn{5}{|c|}{ Magnésio $\left(\mathrm{cmol}_{\mathrm{c}} \mathrm{dm}^{3}\right)$} \\
\hline $0-1$ & 3,13 & 4,66 & 4,20 & 4,27 & 4,38 & 1,37 & 2,07 & 1,93 & 1,81 & 1,94 \\
\hline $1-2$ & 2,83 & 4,31 & 4,07 & 3,88 & 4,09 & 1,23 & 1,88 & 1,81 & 1,61 & 1,77 \\
\hline $2-3$ & 2,55 & 4,15 & 4,00 & 3,65 & 3,93 & 1,13 & 1,90 & 1,71 & 1,47 & 1,69 \\
\hline $3-4$ & 2,18 & 3,55 & 3,51 & 3,08 & 3,38 & 1,02 & 1,56 & 1,48 & 1,37 & 1,47 \\
\hline $4-5$ & 1,99 & 3,29 & 3,18 & 2,83 & 3,10 & 0,95 & 1,46 & 1,32 & 1,28 & 1,35 \\
\hline $5-6$ & 1,78 & 3,14 & 2,88 & 2,51 & 2,84 & 0,89 & 1,39 & 1,24 & 1,18 & 1,27 \\
\hline $6-7$ & 1,86 & 2,83 & 2,69 & 2,23 & 2,58 & 0,84 & 1,25 & 1,17 & 1,13 & 1,18 \\
\hline $7-8$ & 1,62 & 2,69 & 2,46 & 2,27 & 2,47 & 0,81 & 1,19 & 1,09 & 1,10 & 1,13 \\
\hline $8-9$ & 1,70 & 2,67 & 2,25 & 2,18 & 2,37 & 0,81 & 1,17 & 1,01 & 1,08 & 1,09 \\
\hline $9-10$ & 1,61 & 2,39 & 2,19 & 2,10 & 2,23 & 0,71 & 1,10 & 1,01 & 1,02 & 1,04 \\
\hline $10-12,5$ & 1,42 & 2,36 & 2,05 & 2,13 & 2,18 & 0,38 & 0,85 & 0,67 & 0,68 & 0,73 \\
\hline $12,5-15$ & 1,67 & 1,88 & 2,27 & 2,11 & 2,09 & 0,37 & 0,71 & 0,73 & 0,64 & 0,69 \\
\hline $15-17,5$ & 1,33 & 1,85 & 2,20 & 2,23 & 2,09 & 0,35 & 0,72 & 0,74 & 0,66 & 0,71 \\
\hline $17,5-20$ & 1,64 & 2,02 & 2,50 & 1,79 & 2,10 & 0,44 & 0,70 & 0,74 & 0,64 & 0,69 \\
\hline $20-22,5$ & 1,19 & 1,72 & 2,03 & 1,96 & 1,90 & 0,33 & 0,61 & 0,64 & 0,59 & 0,61 \\
\hline $22,5-25$ & 1,16 & 1,67 & 2,12 & 1,98 & 1,92 & 0,32 & 0,61 & 0,66 & 0,50 & 0,59 \\
\hline $25-30$ & 1,23 & 1,90 & 1,91 & 1,56 & 1,79 & 0,29 & 0,57 & 0,57 & 0,46 & 0,53 \\
\hline $30-35$ & 1,00 & 1,30 & 1,85 & 1,50 & 1,55 & 0,24 & 0,47 & 0,42 & 0,45 & 0,45 \\
\hline $35-40$ & 0,89 & 1,16 & 1,45 & 1,20 & 1,27 & 0,24 & 0,44 & 0,49 & 0,40 & 0,44 \\
\hline $40-45$ & 0,75 & 0,93 & 1,31 & 0,96 & 1,07 & 0,21 & 0,34 & 0,44 & 0,35 & 0,38 \\
\hline $45-50$ & 0,81 & 0,96 & 1,24 & 0,95 & 1,05 & 0,21 & 0,32 & 0,38 & 0,32 & 0,34 \\
\hline $50-60$ & 0,64 & 0,79 & 1,04 & 0,59 & 0,81 & 0,19 & 0,30 & 0,37 & 0,21 & 0,29 \\
\hline \multicolumn{2}{|c|}{$\begin{array}{c}\Delta q \text { Tukey } \\
p<0,05) \\
\end{array}$} & & & & 1,06 & & & & & 0,38 \\
\hline
\end{tabular}

superior a $40 \%$, somente na camada $0-1 \mathrm{~cm} \mathrm{e}$ superior a $35 \%$ até os $6 \mathrm{~cm}$. Abaixo dos $10 \mathrm{~cm}$, a saturação com bases caiu para menos de $20 \%$ (Figura 1).

Os valores de $\mathrm{Ca}$ e $\mathrm{Mg}$ trocáveis e $\mathrm{pH}$ do solo ainda estão em níveis superiores ao solo original, mesmo 84 meses após a calagem, mostrando que os efeitos da calagem podem perdurar por vários anos, como observado por (AZEVEDO et al., 1996). As principais causas apontadas para a reacidificação do solo são a perda de nitrogênio do sistema, oriundo da aplicação de fertilizantes ou da fixação biológica (HELYAR, 1976; HAYNES, 1983; PAIVA et al., 1996; BURLE et al., 1997) e das perdas de solo por erosão (RHEINHEIMER et al., 2000c; WIETHÖLTER, 2000). A adoção do SPD diminui as perdas de solo por erosão, aumentando o efeito residual do calcário mas, por outro lado, aumenta os teores de matéria orgânica, principal componente da acidez potencial (PAIVA et al., 1996), o que aumenta a necessidade de calcário, mas não os teores de Al trocável. O reaparecimento do $\mathrm{Al}$ na solução do solo ocorre por causa do abaixamento do $\mathrm{pH}$ do sistema, cuja tendência é recuperar os valores originais, mas esse processo é lento e o efeito da aplicação do calcário se mantém por longos períodos.

Apesar da saturação com alumínio alcançar mais de $15 \%$ e a saturação com bases
Tabela 3 - Alumínio trocável em diferentes camadas de solo sob sistema plantio direto, após 84 meses da aplicação de doses de calcário.

\begin{tabular}{|c|c|c|c|c|c|}
\hline \multirow{2}{*}{$\begin{array}{l}\text { Profundidade } \\
(\mathrm{cm})\end{array}$} & \multirow[b]{2}{*}{ Testemunha } & \multicolumn{4}{|c|}{ Doses de calcário } \\
\hline & & $\begin{array}{l}1 / 2 \text { SMP } \\
\text { bienal }\end{array}$ & $\begin{array}{l}\text { 1/3 SMP } \\
\text { anual }\end{array}$ & $1 \mathrm{SMP}$ & Média \\
\hline & \multicolumn{5}{|c|}{$\mathrm{cmol}_{\mathrm{c}} \mathrm{dm}^{-3}$} \\
\hline $0-1$ & 0,03 & 0,00 & 0,00 & 0,00 & 0,00 \\
\hline $1-2$ & 0,06 & 0,00 & 0,00 & 0,00 & 0,00 \\
\hline $2-3$ & 0,09 & 0,00 & 0,00 & 0,00 & 0,00 \\
\hline $3-4$ & 0,24 & 0,00 & 0,00 & 0,00 & 0,00 \\
\hline $4-5$ & 0,29 & 0,00 & 0,00 & 0,00 & 0,00 \\
\hline $5-6$ & 0,46 & 0,00 & 0,00 & 0,00 & 0,00 \\
\hline $6-7$ & 0,58 & 0,00 & 0,00 & 0,15 & 0,05 \\
\hline $7-8$ & 0,64 & 0,00 & 0,16 & 0,18 & 0,11 \\
\hline $8-9$ & 0,61 & 0,00 & 0,25 & 0,20 & 0,15 \\
\hline $9-10$ & 0,66 & 0,18 & 0,39 & 0,24 & 0,27 \\
\hline $10-12,5$ & 1,13 & 0,17 & 0,23 & 0,33 & 0,24 \\
\hline $12,5-15$ & 1,10 & 0,30 & 0,32 & 0,33 & 0,32 \\
\hline $15-17,5$ & 1,27 & 0,41 & 0,30 & 0,48 & 0,40 \\
\hline $17,5-20$ & 1,09 & 0,49 & 0,38 & 0,52 & 0,46 \\
\hline $20-22,5$ & 1,47 & 0,63 & 0,59 & 0,57 & 0,60 \\
\hline $22,5-25$ & 1,44 & 0,72 & 0,50 & 0,64 & 0,62 \\
\hline $25-30$ & 1,59 & 0,88 & 0,57 & 0,73 & 0,73 \\
\hline $30-35$ & 1,63 & 1,00 & 0,65 & 0,90 & 0,85 \\
\hline $35-40$ & 1,76 & 1,21 & 1,21 & 1,14 & 1,19 \\
\hline $40-45$ & 1,79 & 1,31 & 1,09 & 1,28 & 1,23 \\
\hline $45-50$ & 1,81 & 1,31 & 1,15 & 1,40 & 1,29 \\
\hline $50-60$ & 1,66 & 1,53 & 1,13 & 1,30 & 1,32 \\
\hline $\begin{array}{l}\Delta q \text { Tukey } \\
(p<0,05)\end{array}$ & & & & & 0,28 \\
\hline
\end{tabular}




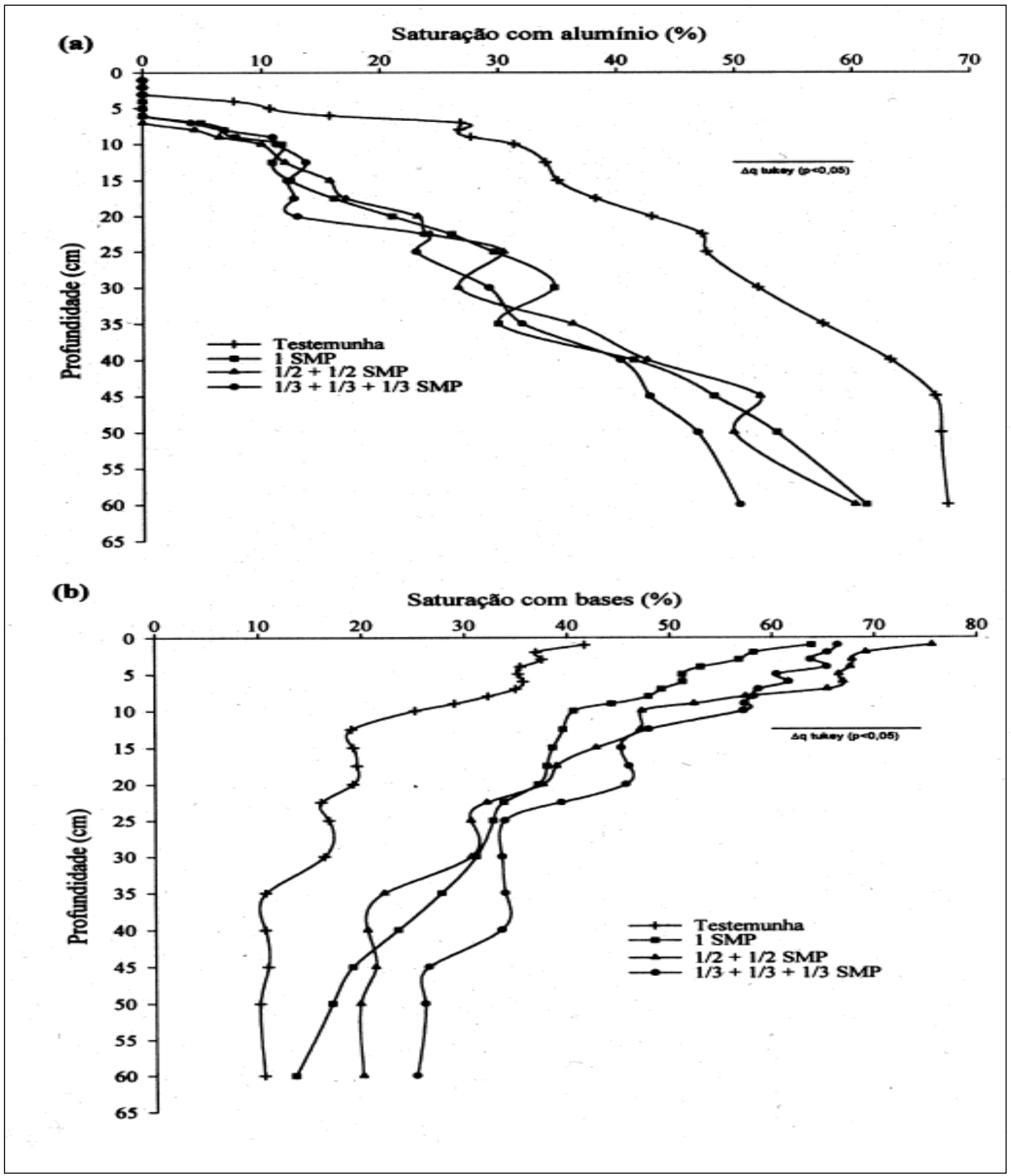

Figura 1 - Saturação com alúminio (a) e saturação com bases (b) em diferentes camadas de solo sob sistema plantio direto, após 84 meses da aplicação de doses de calcário.

ser inferior a das culturas (Tabela 4), como já relatado nos cultivos anteriores (RHEINHEIMER et al., 2000a). Isto pode ter ocorrido porque o desenvolvimento inicial das raízes ocorreu num ambiente com baixos teores de $\mathrm{Al}$ e, quando as raízes atingiram camadas com maiores teores, elas toleraram melhor sua presença, como observado por RHEINHEIMER et al. (1994) e PETRY et al. (1994) com a cultura do fumo. Também SCHERER et al. (1984) observaram $80 \%$ do rendimento máximo de milho em solo com $30 \%$ de saturação com Al.

Ciência Rural, v. 33, n. 2, mar-abr, 2003. 
Tabela 4 - Produtividade de grãos de milho e matéria seca de aveia preta, em solo sob sistema plantio direto, submetido à aplicação de doses de calcário

\begin{tabular}{lcc}
\hline Doses de calcário & Milho safra 99/00 & Aveia preta - 2000 \\
\hline $\mathrm{t} \mathrm{ha}^{-1}$ & & $\mathrm{Mg} \mathrm{ha}^{-1}$ \\
0 & $6,57^{\mathrm{NS}}$ & $8,44^{\mathrm{NS}}$ \\
$1,8+1,8$ & 6,53 & 8,56 \\
$1,2+1,2+1,2$ & 6,71 & 6,24 \\
3,6 & 6,20 & 7,07 \\
$\mathrm{CV}(\%)$ & 13,84 & 11,19 \\
\hline $\mathrm{NS}$
\end{tabular}

${ }^{\mathrm{NS}}$ Não significativo pelo teste Tukey $(\mathrm{p}<0,05)$.

Adicionalmente, no SPD, os valores dos atributos da acidez analisados no solo como um todo pode não representar o real ambiente de crescimento radicular, uma vez que há crescimento preferencial das raízes em bioporos, cujo ambiente é mais favorável quimicamente (GASSEN \& KOCHHANN, 1998, BEARE et al., 1995). Adicionalmente, a utilização de irrigação nos períodos de déficit hídrico contribuiu para a menor fitotoxidez do Al, uma vez que diminui a necessidade de expansão do sistema radicular em busca de umidade e nutrientes (KELTJENS, 1997).

Nos tratamentos em que se reaplicou calcário a partir de 1994, observou-se efeito nos atributos relacionados à acidez em todo horizonte superficial porém, não se constataram diferenças se a dose foi adicionada no início do experimento, ou fracionada em duas ou três aplicações (Tabelas 1, 2 e 3 , Figura 1). $\mathrm{O}$ pH do solo foi superior a 5,5 até $7 \mathrm{~cm}$ de profundidade, superior a 4,9 até os $12,5 \mathrm{~cm}$ e superior a 4,5 nas demais camadas (Tabela 1). A aplicação de calcário na superfície do solo proporcionou um acúmulo de $\mathrm{Ca}$ e $\mathrm{Mg}$ nos primeiros centímetros do solo, atingindo valores de 4,38 e $1,94 \mathrm{cmol}_{\mathrm{c}} \mathrm{dm}^{-3}$ na camada $0-1 \mathrm{~cm}, 2,23$ e $1,04 \mathrm{cmol}_{\mathrm{c}} \mathrm{dm}^{-3}$ na camada $9-10 \mathrm{~cm}$, 2,09 e $0,71 \mathrm{cmol}_{\mathrm{c}} \mathrm{dm}^{-3}$ na camada $15-17,5 \mathrm{~cm}$ e menor que 1,07 e $0,38 \mathrm{cmol}_{\mathrm{c}} \mathrm{dm}^{-3}$ a partir dos $40 \mathrm{~cm}$ de profundidade (Tabela 2). O Al trocável foi totalmente neutralizado até $6 \mathrm{~cm}$ de profundidade. Seus teores foram menores do que $0,30 \mathrm{cmol}_{\mathrm{c}} \mathrm{dm}^{-3}$ até os $10 \mathrm{~cm}$, menores do que $0,50 \mathrm{cmol}_{\mathrm{c}} \mathrm{dm}^{-3}$ até os $20 \mathrm{~cm} \mathrm{e}$ ultrapassando $1,00 \mathrm{cmol}_{\mathrm{c}} \mathrm{dm}^{-3}$ somente abaixo dos 35 $\mathrm{cm}$ de profundidade (Tabela 3). Do mesmo modo, a saturação com $\mathrm{Al}$ foi zero até os $7 \mathrm{~cm}$, inferior a $12 \%$ até os $10 \mathrm{~cm}$, inferior a $15 \%$ até os $20 \mathrm{~cm}$, inferior a $30 \%$ até os $30 \mathrm{~cm}$ e maior do que $40 \%$ nas camadas abaixo dos $40 \mathrm{~cm}$ (Figura 1). A saturação com bases mantevese superior a $60 \%$ até os $7 \mathrm{~cm}$, superior a $50 \%$ até os $10 \mathrm{~cm}$, superior a $40 \%$ até os $20 \mathrm{~cm}$ e menor do que $30 \%$ abaixo dos $40 \mathrm{~cm}$ (Figura 1).

Esses dados concordam com os principais trabalhos desenvolvidos no Sul do País, cujos efeitos em profundidade são dependentes da dose de corretivo aplicada, do tempo de reação e das condições físicas do solo. CAIRES et al. (1998, 1999 e 2000) e NETO et al. (2000) constataram que a diminuição do Al trocável e aumento nos teores de $\mathrm{Ca}$ e $\mathrm{Mg}$ e no $\mathrm{pH}$ do solo ocorreu até os $10 \mathrm{~cm}$ de profundidade, já aos 3-12 meses após a aplicação e atingindo os $20 \mathrm{~cm}$ aos 40-58 meses após a aplicação. No entanto, como no presente trabalho, a neutralização total do Al ficou limitada a camada de 05cm (CASSOL, 1995; AMARAL, 1998; POTTKER \& BEN, 1998; KAMINSKI et al., 2000; RHEINHEIMER et al., 2000b; PETRERE \& ANGHINONI, 2001; MOREIRA et al., 2001).

Dentre as explicações plausíveis, mencionadas na literatura, para a correção da acidez e aumento nos teores de $\mathrm{Ca}$ e $\mathrm{Mg}$ em subsuperfície, a atuação de ânions orgânicos e a descida de partículas finas de calcário, provavelmente, tenham contribuído nesse experimento. Em primeiro lugar, a manutenção do solo constantemente coberto com diferentes tipos de plantas e seus resíduos tem aumentado o teor de matéria orgânica (RHEINHEIMER et al., 1998). Durante a decomposição dos resíduos na superfície do solo, há produção de ânions orgânicos. Os compostos orgânicos hidrossolúveis formam complexos com o Ca da camada superficial, os quais migram para camadas mais profundas, nas quais podem ser trocados pelo $\mathrm{Al}$, diminuindo sua fitotoxidade e aumentando o teor de Ca no perfil do solo (HAYNES \& MOKOLOBATE, 2001). Em segundo lugar, a camada superficial do presente solo apresenta alta macroporosidade, principalmente bioporos originários da decomposição do sistema radicular, especialmente após o cultivo da crotalária, e da atuação da macrofauna. Através desses macroporos, as partículas finas de calcário podem ter sido arrastadas pela água, corrigindo a acidez do solo em subsuperfície, como demonstrado por AMARAL et al. (2001).

\section{CONCLUSÕES}

A aplicação superficial de calcário neutraliza totalmente o alumínio trocável apenas até os $6 \mathrm{~cm}$ de profundidade, mesmo após 84 meses da aplicação da dose recomendada para elevar o $\mathrm{pH}$ do solo a 6,0 .

A aplicação superficial de calcário proporciona uma frente alcalinizante no perfil do solo, diminui os teores de alumínio trocável e sua saturação até $60 \mathrm{~cm}$ de profundidade, aumenta a saturação com bases até os $40 \mathrm{~cm}$ e o $\mathrm{pH}$ até $45 \mathrm{~cm}$.

\section{REFERÊNCIAS BIBLIOGRÁFICAS}

AMARAL, A.S. Reaplicação de calcário no sistema plantio direto consolidado. 1998. 102f. Dissertação (Mestrado em 
Ciência do solo) - Programa de Pós-graduação em Agronomia, Universidade Federal do Rio Grande do Sul.

AMARAL, S.A. et al. Movimentação vertical do calcário da superfície do solo no sistema plantio direto. In: CONGRESSO BRASILEIRO DE CIÊNCIA DO SOLO, 28., 2001, Londrina. Anais... Londrina : SBCS, 2001. p.114.

AZEVEDO, A.C.; KÄMPF, N.; BOHNEN, H. Alterações na dinâmica evolutiva de latossolo bruno pela calagem. Revista Brasileira de Ciência do Solo, Campinas, v.20, p.191-198, 1996.

BEARE, M.H. et al. A hierachical approach to evaluating the significance of soil biodiversity to biogeochemical cycling. Plant and Soil, The Hauge, v.170, p.5-22, 1995.

BURLE, M.L.; MIELNICZUK, J.; FOCCHI, S. Effect of cropping systems on soil chemical characteristics, with emphasis on soil acidification. Plant and Soil, The Hauge, v.190, p.309316, 1997.

CAIRES, E.F. et al. Alterações de características químicas do solo e resposta da soja ao calcário e gesso aplicados na superfície em sistema de cultivo sem preparo do solo. Revista Brasileira de Ciência do Solo, Viçosa, v.22, p.27-34, 1998.

CAIRES, E.F. et al. Produção de milho, trigo e soja em função das alterações das características químicas do solo pela aplicação de calcário e gesso na superfície, em sistema plantio direto. Revista Brasileira de Ciência do Solo, Viçosa, v.23, p.315327, 1999.

CAIRES, E.F.; BANZATTO, D.A.; FONSECA, A.F. Calagem na superfície em sistema plantio direto. Revista Brasileira de Ciência do Solo, Viçosa, v.24, p.161-169, 2000.

CASSOL, L.C. Características físicas e químicas do solo e rendimento de culturas após a reaplicação de calcário, com e sem incorporação, em sistema de preparo. 1995. 97f. Dissertação (Mestrado em Ciência do solo) - Programa de Pós-graduação em Agronomia, Universidade Federal do Rio Grande do Sul.

COMISSÃO DE FERTILIDADE DO SOLO - RS/SC. Recomendações de adubação e calagem para os estados do Rio Grande do Sul e Santa Catarina. 3. ed. Passo Fundo : SBCS - Núcleo Regional Sul/EMBRAPA/CNPT, 1994. $224 p$.

FERREIRA, T.N.; FARIAS, A.D.; SCHWATZ, R A. Sistema plantio direto no Rio Grande do Sul- 1999. Porto Alegre : EMATER, 1999. 4p. (Informativo Técnico, 17).

GASSEN, D.N.; KOCHHANN, R.A. Benefícios de insetos de solo sob plantio direto. In: NUERNBERG, N.J. (Ed.). Conceitos e fundamentos do sistema plantio direto. Lages : NRS/SBCS, 1998. Cap.4, p.151-160.

HAINES, R.J. Soil acidification induced by leguminous crops. Grass and Forage Science, Oxford, v.38, p.1-11, 1983.

HAYNES, R.J.; MOKOLOBATE, M.S. Amelioration of Al toxity and $\mathrm{P}$ deficiency in acid soils by additions of organic residues: a critical review of the phenomenon and the mecanisms involved. Nutrient Cycling in Agoecosystems, Dordrecht, v.59, p.47-63, 2001.
HELYAR, K.R. Nitrogen cycling and soil acidification. The Journal of the Australian Institute of Agricultural Science, Hawthorn, v.42, p.217-221, 1976.

KAMINSKI, J.; RHEINHEIMER, D.S. A acidez do solo e a nutrição mineral de plantas. In: KAMINSKI, J. (Ed.). Uso de corretivos da acidez do solo no plantio direto. Pelotas : SBCS/NRS, 2000. Cap.2, p.21-39.

KAMINSKI, J. et al. Resposta de culturas à aplicação de calcário em superfície ou incorporado ao solo em campo nativo. Ciência Rural, Santa Maria, v.30, p.605-609, 2000.

KELTJENS, W.G. Plant adaptations and tolerance to acid soils. It's possible Al tolerance: A review. In: MONIZ, A.C. (Ed.). INTERNATIONAL SYMPOSIUM ON PLANT-SOIL INTERACTIONS AT LOW PH, 1997. Proceedings... Viçosa: SBCS, 1997. Cap.8, p.109-117.

MOREIRA, S.G. et al. Calagem em sistema de semeadura direta e efeitos sobre a acidez do solo, disponibilidade de nutrientes e produtividade de milho e soja. Revista Brasileira de Ciência do Solo, Viçosa, v.25, p.71-81, 2001.

NETO, P.H.W. et al. Correção da acidez do solo em função de modos de incorporação de calcário. Ciência Rural, Santa Maria, v.30, p.257-261, 2000.

OLIVEIRA, E.L.; PAVAN, M.A. Control of soil acidity in notillage system for soybean production. Soil Tillage Research, Amsterdan, v.38, p.47-57, 1996.

PAIVA, P.J.R. et al. Acidificação de um Latossolo Roxo do estado do Paraná sob diferentes sistemas de manejo. Revista Brasileira de Ciência do Solo, Campinas, v.20, p.71-75, 1996.

PEARSON, R.W.; ABRUNA, F.; VICE-CHANCES, J. Effect of lime and nitrogen applications on downward movements of calcium and magnesium in two humid soils of Puerto Rico. Soil Science, Oxford, v.93, p.77-82, 1962.

PETRERE, C.; ANGHINONI, I. Alteração de atributos químicos no perfil do solo pela calagem superficial em campo nativo. Revista Brasileira de Ciência do Solo, Viçosa, v.25, p.885$895,2001$.

PETRY, C. et al. Influência do estresse de alumínio em plantas de fumo: I. Efeito dos parâmetros cinéticos de absorção de fósforo. Revista Brasileira de Ciência do Solo, Campinas, v.18, p.69-72, 1994.

PÖTTKER, D.; BEN, J.R. Calagem para uma rotação de culturas no sistema plantio direto. Revista Brasileira de Ciência do Solo, Viçosa, v.22, p.675-684, 1998.

RHEINHEIMER, D.S. et al. Modificações em atributos químicos de solo arenoso sob sistema plantio direto. Revista Brasileira de Ciência do Solo, Viçosa, v.22, p.713-721, 1998.

RHEINHEIMER, D.S. et al. Influência do estresse de alumínio em plantas de fumo: I. Efeito no sistema radicular, na absorção de fósforo e cálcio e na produtividade de matéria seca. Revista Brasileira de Ciência do Solo, Campinas, v.8, p.63-68, 1994.

RHEINHEIMER, D.S. et al. Aplicação superficial de calcário no sistema plantio direto consolidado em solo arenoso. Ciência Rural, Santa Maria, v.30, p.263-268, 2000a. 
RHEINHEIMER, D.S. et al. Alterações de atributos do solo pela calagem superficial e incorporada a partir de pastagem natural. Revista Brasileira de Ciência do Solo, Viçosa, v.24, p.797-805, 2000 b.

RHEINHEIMER, D.S. et al. Acidez do solo e consumo potencial de calcário no Estado do Rio Grande do Sul. Santa Maria : Departamento de Solos - Universidade Federal de Santa Maria, 2000c. 32p. (Boletim técnico, 1).

SCHERER, E.E. et al. Dinâmica da correção da acidez do solo e seus efeitos na produção de milho. Florianópolis : EMPASC, 1984. 23p. (Boletim Técnico, 27).

TEDESCO, M.J. et al. Análise de solo, plantas e outros materiais. 2.ed. Porto Alegre : Departamento de Solos, Universidade Federal do Rio Grande do Sul, 1995. 174p. (Boletim Técnico, 5).

WIETHÖLTER, S. Calagem no Brasil. Passo Fundo : EMBRAPA Trigo, 2000. 104p. (Documentos, 22).

Ciência Rural, v. 33, n. 2, mar-abr, 2003. 